\title{
Accelerating Innovation and Start-ups through Entrepreneurship Education
}

\author{
Prof. Dr. Annette Blöcher ${ }^{1}$, Lukas Simon Gawlik ${ }^{2}$ and Prof. Dr. Marcus Störkel ${ }^{3}$ \\ ${ }^{1}$ Entrepreneurship \& Corporate Management, TH Köln, Germany, annette.bloecher@th-koeln.de \\ 2Entrpreneurship, TH Köln, Germany, lukas_simon.gawlik@smail.th-koeln.de \\ ${ }^{3}$ International School of Management Cologne, Germany, marcus.stoerkel@ism.de
}

\begin{abstract}
.
This paper aims to stimulate debate among researchers and practioners within the process and development of innovations and the question of how to support future entrepreneurs through education. It is argued that universities play a major role within the innovation ecosystem. In fact, universities can be regarded as central partners due to their mission to teach and to research. Universities are increasingly initiating and promoting entrepreneurial thinking and acting of their students and contribute significantly to their students' qualification as founders. Entrepreneurship education and the provision of facilities and services for young founders play an increasing role in promoting innovation as a knowledge-based output. Many studies have widely recognised that entrepreneurship education has great impacts on an individual, organisational, and societal level. It contributes to creating new jobs to economic success as well as to globalization, innovation and renewal. The present study examines the question of how universities - using one specific university as an example - can support the start-up activities of their students in order to develop and establish an entrepreneurial mindset and culture over time. This paper looks at two empirical studies: first, a recent survey from 2019 and second, a survey from 2016, allowing comparative statements over time. As a conclusion, the authors recommend a course of action to other universities to encourage and strengthen the start-up efforts of their students. Only by offering entrepreneurship education and creating an infrastructure for innovative ideas of their students and staff alike, can universities become serious innovation partner.
\end{abstract}

Keywords: Entrepreneurship; Entrepreneurship Education; Innovation Ecosystem; Start-up; University 


\section{Entrepreneurship Activities at Universities}

\subsection{Relevance of Entrepreneurship Education}

Actively designing and developing entrepreneurship education is the starting point and center of an entrepreneurial mindset and culture at universities. University teaching is based on theory and research. It gets more and more interdisciplinary in order to solve complex challenges. To teach entrepreneurial skills teaching must enable self-organized learning, which not only aims to acquire expertise, but also social and personal skills (cf. Puteanus-Birkenbach \& Hölzle, 2014, p. 93; Gibb, 1993). Scholkmann (Scholkmann, 2016) emphasizes that entrepreneurship education is a teaching and learning concept that is characterized by promoting a focus on solutions, on creativity, a willingness to make experiments, a high degree of innovative and implementation orientation, and a tolerance to possible mistakes that occur in the process (cf. Scholkmann, 2016). Through the evaluation of various studies, Lackéus (Lackéus, 2015) has shown that entrepreneurship education is highly relevant on an individual, organizational and societal level, as shown in table 1.

Table 1: Relevance and Importance of Entrepreneurship Education

\begin{tabular}{|l|l|l|l|l|l|}
\hline \multicolumn{2}{|c|}{ Individual level } & \multicolumn{1}{|c|}{ Organizational level } & \multicolumn{2}{c|}{ Societal level } \\
\hline Commonly stated reasons for entrepreneurial education, but less effective in schools and for embedded approaches
\end{tabular}

Source: Lackéus, 2015, p. 18

Entrepreneurship education has positive impacts on job creation, economic success, on globalization, innovation and the renewal of a society in general. Furthermore, there are rarely stated but promising bonusses for entrepreneurship education: joy, engagement, creativity, as well as societal challenges (Lackéus, 2015). An important goal of this is to promote the innovation process the modeling of new business models (cf. Wirtz \& Daiser, 2018).

In literature, entrepreneurship is an object of theory and research and is discussed both in Germany and internationally in the scientific community. This is evident in studies conducted in this area. Particularly noteworthy for German universities are the "German Startup Monitor", the "KfW Startup Monitor", the "Global Entrepreneurship Monitor". 
In addition, the "Global University Entrepreneurial Spirit Students' Survey" collects data to enable an international comparison among students in 54 countries every two years (Sieger et al., 2019, p.3). Since 2016, TH Köln has also been participating in this survey which examines entrepreneurial intentions and efforts among students. This is where the greatest intersection with the present study can be found: The topic of entrepreneurship is considered in the university environment of the students and surveys a status quo of the founding activities at universities.

\subsection{Universities as Centers of the Innovation Ecosystem}

Due to their mission of research and teaching, universities can be regarded as a central partner in innovation. They provide an infrastructure that creates a network for experts, young talents, mentors, established innovative companies as well as start-ups (cf. Morrison, 2019). Universities are increasingly initiating and promoting the entrepreneurial thinking and acting of their students and thus contribute significantly to their qualification as founders. Entrepreneurship education and the provision of facilities and services for young founders play an increasing role and are intended to promote innovation as a knowledge-based output (cf. Reisswig 2014; BMWi 2019).

Universities are expected to offer a comprehensive and practice-oriented, more and more interdisciplinary range of courses in order to prepare students in the best way possible for their future professions. Innovation, creativity, the development of solutions, strength in implementation as well as proactivity are increasingly demanded by future employer and the economy as a whole. Those skills can be summed up to "entrepreneurial skills" (cf. Fritsch, 2016 , p. $44 \mathrm{ff}$.). It is the responsibility of universities to prepare future generations of academics for these requirements (cf. Blöcher et al., 2019, p. 53 ff.; Reisswig, 2014). Entrepreneurship education is widely internationally discussed in this context (cf. Lackéus; 2015; Rae, 2000; Gravan \& O'Cinneide, 1994; Cumming \& Zhan, 2018; Young \& Sexton, 1997).

Universities are a central element in the innovation ecosystem by being a place of education and a place of physical and digital networking. Their research-based infrastructure enables talented students, mentors, start-ups, growth companies and investors to meet and to develop business models from (research-based) ideas (cf. Morrison, 2019). 


\section{$4^{\text {th }}$ International Conference on \\ BUSINESS, MANAGEMENT \& ECONOMICS}

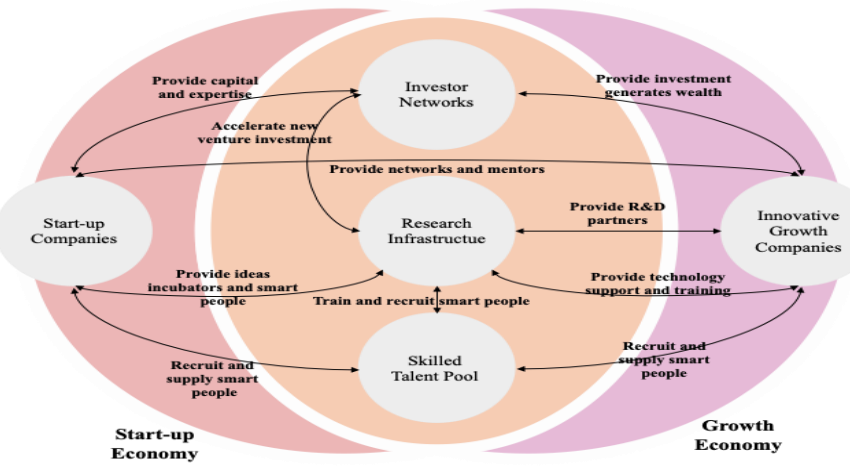

Source: Morrisson, 2019

Thereby, universities offer space for ideas and networks to grow. A clear definition of entrepreneurship and the development of an entrepreneurial mindset and culture at universities, which integrates internal stakeholders, i.e. students, professors and staff, as well as external stakeholders, i.e. companies, investors and society, is essential. Both form the basis to enable and promote entrepreneurial thinking and acting.

The essential premise is that entrepreneurship can be learned and thus taught. Following Putenaus-Birkenbach entrepreneurship is defined as:

"Entrepreneurship is entrepreneurial thinking and acting and is the learnable art of discovering opportunities and the intellectual anticipation of a business model from the idea (or technology), - and idea development up to the concept by creative factor combination, combined with an art of acting, namely the enforcement of the concept with the awareness that mistakes are possible and necessary."(Puteanus-Birkenbach \& Hölzle, 2014, p. 93)

Based on this definition of entrepreneurship, the term culture of entrepreneurship of a university in this study is defined as:

The culture of entrepreneurship of a university is understood as the sum of shared values that lead to activities of creating an awareness, of mobilization and promotion of entrepreneurial thinking and acting of the universities' members and, finally, to the establishment of enterprises. These values have an effect on infrastructure and services within the framework of entrepreneurship education, which are practice-oriented, both disciplinary and interdisciplinary, and promote coworking, even networking of those involved within and outside the university. This culture demands and promotes the entrepreneurial skills of its community members.

\subsection{Entrepreneurship at German Universities Using the Example of TH Köln}


TH Köln is the biggest university of technology, arts and sciences in Germany. It forms a community of more than 26,000 students, 440 professors and 2,000 employees. It holds 360 international cooperations with other universities and sees itself as a learning organization. With its disciplinary and cultural diversity, it makes substantial contributions to solving social challenges. The broad spectrum of subjects, such as offered by 12 faculties in the fields of applied natural sciences, architecture and civil engineering, information and communication, computer science, engineering, culture, society and social affairs as well as economics, is a valuable basis for interdisciplinarity, joint projects and founding ideas (TH Köln, 2020).

"TH Köln sees itself as a 'University of Technology, Arts, Sciences', in which teaching and research are inseparably linked. Internationally oriented and regionally anchored, it fulfills a social mission with a strong research focus and sustainable teaching: to generate knowledge through research and make it effective for business, civil society, culture and politics." (TH Köln - University Development Plan 2030 (2018, A), p.7).

As a committed university in and for society, TH Köln focuses on promoting entrepreneurial thinking and acting among students by means of far-reaching measures in the sense of entrepreneurship education, which includes teaching, consulting and networking events and further support. Thus, in accordance with the University Development Plan 2030, TH Köln is positioning itself as a start-up-friendly university and is pushing the expansion of its offers in the field of entrepreneurship, regardless of the discipline and course of study. A special focus is placed on research- and knowledge-based start-ups, which have a high degree of innovation and high growth expectations (TH Köln, 2018, A, p.16).

Entrepreneurship education is an important component of university teaching at TH Köln. Since 2014, this topic has received increased attention in the university's focus - starting with the faculty of economics and law - and has been made more and more tangible for students. Within the project "Entrepreneurship and Start-up Culture at TH Köln", a broad-based study (cf. Blöcher \& Gawlik 2017, A, B) was carried out in 2016. It examines the status quo of the entrepreneurial culture at the university, queried the suggestions and needs of the students and served as a basis for the definition and implementation of further activities. Since then, TH Köln has intensified its efforts to establish a lively academic culture of entrepreneurship, a culture that demands and promotes entrepreneurial thinking and action from its students and staff. The following activities serve as examples:

\section{- Establishment of the new 'Task Force Entrepreneurship'}

In 2016, the interdisciplinary task force for entrepreneurship was (TH Köln - Task Force Entrepreneurship, 2020) set up with more than 20 professors and staff members from almost all faculties of the TH Köln. Through this forum, the members are involved in interdisciplinary activities in order to anchor entrepreneurial thinking and acting in the individual disciplines, but also in interdisciplinary teaching in the sense of entrepreneurship education. The goal is to promote the students' competence to transfer theory into action, but also to offer them specific support if they take advantage of entrepreneurial opportunities: From the development of ideas to the implementation of a 
sustainable business model, the students should perceive the university as their first partner to obtain support, encouragement and information on further offers.

\section{- Constitution of the university-wide 'Strategy of Entrepreneurship Education and} Business Start-ups'

In 2018, the management of the TH Köln together with the task force entrepreneurship agreed on the "Strategy of Entrepreneurship Education and Start-ups" (TH Köln, 2018, B), in which centralized and decentralized structures and incentive systems were defined. On this basis, the TH Köln could establish itself as an important network-element within the

entrepreneurial ecosystem in Cologne as well as in the area in order to actively shape the start-up landscape (TH Köln, 2018, B, p. 5). Specifically, the start-up service of TH Köln will be centrally anchored, but decentralized offers in form of mini incubators will also be set up locally at the respective faculties and locations of the TH Köln and be networked with the central business start-up service and with each other.

\section{- Establishment of Entrepreneurship-Focused Professorships}

At the TH Köln, professorships for entrepreneurship currently exist at three faculties. Further professorships for entrepreneurship are planned. In addition, many other professors with adjoining subjects such as business management or innovation management are more and more committed to this topic. Through this institutional measure, the idea of entrepreneurship is carried into the most diverse disciplines and locations of the university and students are made aware of the topic early on in their academic careers.

\section{- Establishment of Start-up Consulting at the Faculty of Economics and Law}

In the course of the establishment of the taskforce entrepreneurship, the start-up consultancy was established at the faculty of economics and law (TH Köln - Start-up Consulting, 2020).

Professors with different areas of expertise can thus offer assistance and support to students of the Faculty of Economics and Law who are interested in setting up their own business. Due to the wide range of consulting services offered, students can tap into comprehensive advice.

\section{- Interdisciplinary Lecture Series 'Entrepreneurship \& Innovation'}

The teaching offered at several faculties was extended by modules that also deal with the topic of entrepreneurship. One of those courses is the interdisciplinary lecture series 'Entrepreneurship \& Innovation' (TH Köln - Interdisciplinary Lecture Series Entrepreneurship \& Innovation, 2020), which is open to all students of TH Köln. External speakers are invited to talk about entrepreneurial strategies and activities of their company. In a subsequent discussion questions are answered and the students have a direct exchange on entrepreneurial issues with business representatives. This offer also serves the purpose of cross-faculty networking, as students from different faculties participate in the events. 


\section{- Regular Networking Event 'Entrepreneurs-Club TH Köln'}

Another measure for cross-faculty networking and for the development of students' synergy across the locations of the university is the Entrepreneurs-Club TH Köln (TH Köln - Entrepreneurs-Club, 2020), a university-wide networking event. The event opens with a keynote speaker of an already successful entrepreneur and/or investor. Afterwards, two to three students'start-ups pitch their business models, receive feedback and enter into discussion with the audience. Afterwards, there is an opportunity for networking and discussion.

\section{- Strengthening the Start-up Service}

The start-up service of TH Köln offers advice and support on funding opportunities as well as information on the topic of self-employment, start-ups and entrepreneurship, and serves as a central starting-point at TH Köln for students who are considering starting their own business. Through the personnel measures, however, the areas of networking, marketing and events can now be tackled more intensively (TH Köln - Start-up Service, 2020).

\section{- Set-up of Decentralized Mini-Incubators and Centralized Incubator}

Following the strategy of entrepreneurship education and business start-ups, decentralized mini-incubators were established at various locations of the TH Köln. In 2020 these miniincubators have been supplemented by a centralized incubator named StartUpLab@TH Köln, where students of all faculties can meet and work on their prototypes (TH Köln - StartUpLab@TH Köln, 2020).

\section{- Expansion of International Cooperations}

The entrepreneurship activities were also expanded internationally by a cooperation agreement with the Tongmyong University, Busan, South Korea, and with the Center for Entrepreneurial Development at the Universidad Pontificia Bolivarina, Colombia.

\section{Research Question and Methodology}

The present study examines the question of how universities, using the example of TH Köln, can teach their students entrepreneurial skills and make them aware of opportunities, mobilize, and support them with regard to start-up activities in order to develop and establish an entrepreneurial mindset and culture over time. This study includes two empirical studies: a recent student survey from 2019 and a survey from 2016. Its aim is to show the status quo of the entrepreneurial mindset and culture at the TH Köln as well as its development over time. With this research question, the study aims to give tangible recommended courses of action for the university itself in order to actively establish and promote a culture of entrepreneurship at a university and to act as a relevant agent in the regional entrepreneurial 
ecosystem. Special emphasis is also given the students' perspective by asking them to make own suggestions.

The methodology chosen for the defined research objective is fundamental to the result of the study. A quantitative research strategy has been chosen because a large sample had to be examined and evaluated with standardized methods. A standardized survey with closed and open questions has been used.

The present study has been carried out in 2019 with a sample of 1,734 students of TH Köln. In the previous study of 20162,071 students have been questioned. The comparison of both studies allows to come up with statements on whether the implemented measures work on improving a culture of entrepreneurship at TH Köln. It is important to emphasize the

essentially given comparability of the samples, but with the restriction that not the same students could be interviewed within the second inquiry (no panel study), see Table 2.

Sample of the previous study (2016)

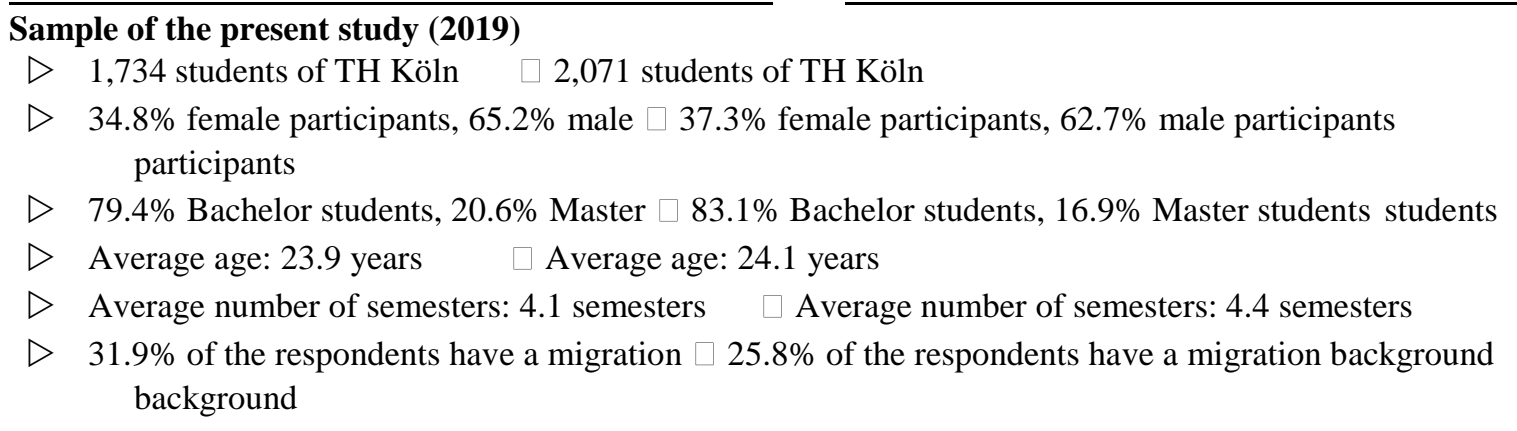

In view of the already available figures from 2016 and the universities' strategy development on the topic of entrepreneurship, the following key questions were defined for the survey:

- What is the status quo of the entrepreneurship activities at TH Köln that serve to establish a culture of entrepreneurship?

- How has the culture of entrepreneurship at TH Köln developed over time?

- How do the students of the TH Köln evaluate the measures to strengthen the culture of entrepreneurship?

- What ideas and suggestions do the students have for promoting their start-up activities?

Questions from the survey of 2016 served as review questions to compare and to examine developments over the course of three years. In addition, based on the Strategy of Entrepreneurship Education \& Business Start-ups of TH Köln, defined packages of measures were transformed into more tangible proposals for offers and presented to the students for 
evaluation. For all packages of measures, students were also given the opportunity to submit additional proposals by free responses.

In 2019, a total of 1,734 students from 11 faculties and six locations were surveyed, in 2016, a total of 2,071 students from TH Köln. The surveys were filled out online by students and also in the form of questionnaires that were taken to various events at TH Köln in order to achieve the most representative results possible. In doing so, the distribution of characteristic attributes was as close as possible to the values from the statistics of TH Köln, i.e. gender, faculty, semester, and graduation goal were chosen as control parameters for the depiction of a sample as close to reality as possible.

In the course of the evaluation, first cumulative results of the individual questions were examined, which were compared in a second step with regard to socio-demographic differences. Subsequently, a comparison was made in parts with the results from 2016.

The quality criteria of the quantitative investigations' (cf. During \& Bortz, 2015) reliability, validity and objectivity are met to a high degree. Reliability was established because the questions were clearly formulated and tested in advance. Thus, it can be assumed that a new survey would provide similar to identical results, i.e. replicability of the results is largely given. The objectivity of the survey is largely guaranteed, since on the one hand, the online survey had no influence on which students of the TH Köln answered, and on the other hand, an attempt was made to achieve the greatest possible representativeness of the interviewees about the faculties compared to the university statistics by issuing printed questionnaires in complete courses. It can also be assumed that the questionnaires were as valid as possible, since the categories of the answers were carefully derived from literature (and supplemented), and in many cases the participants were free to make additions.

\section{Key Findings of the Empirical Studies}

The most important results of the study based on 2019 data at a glance:

- $10.2 \%$ of students at TH Köln are self-employed; $14.0 \%$ have already taken first steps towards self-employment; the proportion of students who (currently) exclude selfemployment as a career option is $32.7 \%$.

- Of the self-employed students, $63.5 \%$ are female and $36.5 \%$ male.

- The proportion of female students who have taken first steps towards self-employment is $11.1 \%$; the proportion of male students is $16.8 \%$.

- With a rate of $14.4 \%$, master students are significantly more likely to become selfemployed than bachelor students $(8.3 \%)$. This effect is reversed for students who are taking their first steps towards self-employment: with $15.9 \%$, the proportion in the group of bachelor's students is ahead of the group of master's students $(12.6 \%)$. 
Compared to the 2016 survey, the gap between the two groups has widened, but the shares of both groups have increased compared to 2016.

- $30.2 \%$ of Bachelor students (currently) exclude self-employment as a viable career option for themselves. Among master students $34.7 \%$ do so.

- Role models with regard to self-employment in the direct environment of students have a great influence on students' ambitions for self-employment. In particular, students who are already self-employed and those who are taking their first steps toward selfemployment have a high proportion of reference persons in their immediate environment who have had positive experiences with self-employment (82.4\% and $84.9 \%$, respectively).

- The package of future measures planned by TH Köln meets the needs of the students:

- With regard to the infrastructure at the university, networking events (75.6\%), coworking spaces $(66.3 \%)$ and a central incubator as a start-up support unit open to all faculties $(56.7 \%)$ lists the greatest interest among students.

- With regard to curricular and extracurricular courses, students are particularly interested in modules on business start-ups and entrepreneurship (71.5\%), the opportunity to participate in modules not related to the course of study (70.4\%), workshops on start-up topics $(68.2 \%)$ and practical implementation of a business idea integrated into the course of study $(67.2 \%)$.

- There is great interest among students in an expanded range of curricular courses on entrepreneurship. The students expressed their interest with over $50 \%$ to over $70 \%$ in all answer options in this category.

- For the consulting and support offer of the university the students wish themselves above all access to investors (76.1\%), technical support offer (68.9\%), contact network of founders of the TH Köln, alumni, lecturers and practitioners $(67.7 \%)$ and a digital platform for the search of joint founders with complementary authority $(64.7 \%)$.

- The improved findability of information concerning entrepreneurship is wished by $76.9 \%$ of the students regarding the information and communication of the university. In addition, large interest meets with $70,2 \%$ in addition, an email distributor for establishment-interested. 
- Self-employed students are particularly interested in improved findability of startup information $(87.7 \%)$, access to investors $(87.5 \%)$, networking events $(86.7 \%)$ as well as modules on business start-up and entrepreneurship (82.1\%).

The following can be seen in a comparison between data of 2016 and 2019:

- Since 2016, both the proportion of students who are already self-employed has increased from $7.1 \%$ to $10.2 \%$ (2019) and the proportion of students who have already taken their first steps towards self-employment (from $11.5 \%$ in 2016 to $14.0 \%$ in 2019).

- At the same time, the proportion of students who don't want self-employment has fallen from $38.4 \%$ (2016) to $32.7 \%$ (2019). The proportion of students who are only considering self-employment has changed only marginally.

- The percentage of female students who are already self-employed has increased from $5.4 \%$ in 2016 to $6.9 \%$ in 2019 . The proportion of male students who are already selfemployed has increased from $8.1 \%$ in 2016 to $12.0 \%$ in 2019. Although both groups have increased in share, the gender gap has widened by 5.1 percentage points.

- The proportion of female students who have taken their first steps towards selfemployment has increased from $8.4 \%$ in 2016 to $11.1 \%$. Similarly, the proportion of male students has increased from $13.2 \%$ to $16.8 \%$. Here, too, the gender difference between the two groups has increased, despite growth in the proportion of both groups.

Overall, it can be seen that the measures for raising awareness and mobilization as well as student support, which were derived from the initial data of 2016, are well accepted by students. They have had a positive impact and a positive influence on strengthening a culture of entrepreneurship at TH Köln.

\section{Conclusion: Recommendations for Universities to Support Students in their Efforts at Innovation and Entrepreneurship}

Based on the results of the two studies, targeted future measures of TH Köln for strengthening the culture of entrepreneurship are to be evaluated and to be developed further. The following points can provide additional information on how to anchor entrepreneurship at universities, but also on how to strengthen the entrepreneurial mindset of students:

Table 3: Recommendations for Universities

\section{Establish the university as an innovation partner!}

If students decide to develop their own business idea, their university should be perceived as their first partner for setting up a business. The University should provide infrastructure and offer courses and workshops along the entire education process of founders - from awareness, mobilization, qualification and finally consulting and coaching. External partnerships should be established and maintained for the transfer to the economy. 


\section{Recognize the relevance and importance of entrepreneurship education!}

Entrepreneurship education goes far beyond teaching technical skills. It has positive impacts on job creation, economic success, globalization, innovation and renewal of a society as well as on joy, engagement, creativity and societal challenges It prepares students to start their own business, but also enables them to work in established companies in a future- and solution-oriented manner.

\section{Turn professors into multipliers of interdisciplinarity and entrepreneurship!}

Professors have direct access to the students. Through their collaboration, interdisciplinary lectures and workshops, interdisciplinary teams can form. Through their experience and their contacts to the economy, they are important partners for the students, as well as great mentors.

\section{Create networking structures!}

Establishing an interdisciplinary task force for entrepreneurship increases the visibility of the topic and promotes exchange across disciplinary boundaries. Also, digital networking platforms can promote start-up activities by giving the possibilities to match students with different skills.

\section{Ask students about their needs!}

Students have a lot of ideas of how they want to be supported within their projects. A survey can help to better understand their needs and to formulate adequate offers to the target group. Not all students want to become an entrepreneur. It is important to promote entrepreneurial thinking and acting on a broad scale. On the one hand, this can be done with very low-key offers such as a lecture series, but also with special courses on business model development or the business plan. 


\section{References}

[1] Blöcher, A. and Gawlik, L.S. (2017A). Entrepreneurship und Start-up Kultur an der TH Köln. Auswertung der empirischen Erhebung Teil I: TH Köln gesamt. Schriftenreihe Entrepreneurship \& Innovation (1/2017). [Online]. Available: https://epb.bibl.thkoeln.de/frontdoor/index/index/docId/1029

[2] Blöcher, A. and Gawlik, L.S. (2017B). Entrepreneurship und Start-up Kultur an der TH Köln. Auswertung der empirischen Erhebung Teil II: Auswertung der 11 Fakultäten.

Schriftenreihe Entrepreneurship \& Innovation (2/2017). [Online]. Available: https://epb.bibl.th-koeln.de/frontdoor/index/index/docId/1030

[3] Blöcher, A. and Seidler-de Alwis, R. and Szczyrba, B. (2019). Entrepreneurship Education in der Hochschullehre - interdisziplinär und praxisorientiert. In: Berendt, B., Fleischmann, A., Schaper, N., Szczyrba, B. \& Wildt, J. (eds.), Neues Handbuch Hochschullehre (Griffmarke E 1.15). Berlin: DUZ Medienhaus, 7/2019, pp. 53-70.

[4] BMWi (2019). EXIST -Gründungskultur. [Online]. Available: https://www.exist.de/DE/Programm/Exist-Gruendungskultur/inhalt.html

[5] Bosma, N. and Kelley, D. (2019). Global Entrepreneurship Monitor 2018/19 Global Report. Global Entrepreneurship Research Association. Chile: Gráfica Andes.

[6] Cumming, D. and Zhan, F. (2018): International Entrepreneurship Education, Journal of Teaching in International Business, 29:3, 181-184. [Online]. Available: https://doi.org/10.1080/08975930.2018.1514817

[7] Döring and Bortz (2015). Forschungsmethoden und Evaluation in den Sozial- und Humanwissenschaften. 5th edition. Berlin, Heidelberg: Springer Gabler.

[8] Fritsch, M. (2016). Entrepreneurship - Theorie, Empirie, Politik. Berlin, Heidelberg: Springer Gabler.

[9] Garvan, T.N. and O'Cinneide, B. (1994). Entrepreneurship Education and training programmes: a review and evaluation - part 1. Journal of European Indurstial Training: Vol. 18 No. 8, pp. 3-12.

[10] Gibb, A. (1993). The enterprise culture and education. Entrepreneurship Theory \& Practice: Vol. 13 No. 4, pp. 11-34.

[11]Lackéus, M. (2015). Entrepreneurship in Education - What, Why, When, How -
Entrepreneurship
Background
Paper.
[Online].
Available: https://www.oecd.org/cfe/leed/BGP_Entrepreneurship-in-Education.pdf

[12] Morrison (2019). Developing a University's two ecosystems. [Online]. Available: http://www.edmorrison.com/developing-a-universitys-two-ecosystems/

[13] Puteanus-Birkenbach, K. and Höltzle, K. (2014). Entrepreneurship, Entrepreneur oder der Begriff des unternehmerischen Denken und Handelns. In: Hölzle, K. I 
PuteanusBirkenbach, K. / Wagner, D. (eds.) (2014): Das Potsdamer Modell der Gründungslehre und -beratung: Potsdam, pp. 85-95.

[14] Rae, D. (2000). Understanding entrepreneurial learning: a question of how? In: International Journal of Entrepreneuial Behaviour \& Research. Vol. 6 No.3, 2000, pp. 145-159.

[15] Reisswig, K. (2014). Die unternehmerische Mission von Universitäten als ein Synonym für ihr gewandeltes Selbstverständnis. In: Hölzle, K. and Puteanus-Birkenbach, K. and Wagner, D. (eds.) (2014): Das Potsdamer Modell der Gründungslehre und -beratung: Potsdam, pp. 21-32.

[16] Scholkmann, A. (2016) Forschend-entdeckendes Lernen: (Wieder-)Entdeckung eines didaktischen Prinzips. In: Berendt, B., Fleischmann, A., Schaper, N., Szczyrba, B. \& Wildt, J. (eds.) (2016), Neues Handbuch Hochschullehre (Griffmarke A 3.17). Berlin: DUZ Medienhaus.

[17] Sieger, P. and Fueglistaller, U. and Zellweger, T. and Braun, I. (2019). Global Student Entrepreneurship 2018: Insights From 54 Countries. St.Gallen/Berne: KMU-HSG/IMU.

[18] TH Köln - University Development Plan 2030 (2018A). Hochschulentwicklungsplan 2030. [Online]. Available: https://www.th-

koeln.de/mam/downloads/deutsch/hochschule/profil/hochschulentwicklungsplan2030.pd $\underline{\mathrm{f}}$

[19] TH Köln (2018B). Strategie Entrepreneurship Education \& Existenzgründung. [Online]. Available: https://www.th-

koeln.de/mam/downloads/deutsch/forschung/strategie_entrepreneurship_education_und existenzgruendungen_aktualisiert.pdf

[20]TH Köln (2020). Profil der TH Köln. [Online]. Available: https://www.thkoeln.de/mam/downloads/deutsch/hochschule/profil/th-kolnkurzinfo_2019 web.pdf

[21] TH Köln (2019B). Hochschulstatistik aktuell - Studienjahr 2018/19. [Online]. Available: https://intern.th-koeln.de/finanzen/hochschulstatistik_1534.php

[22] TH Köln - Task Force Entrepreneurship Arbeitskreis Entrepreneurship (2020). [Online]. Available: https://www.th-koeln.de/wirtschafts-undrechtswissenschaften/arbeitskreisentrepreneurship-education_36434.php

[23] TH Köln - Cologone Game Incubator (2020). [Online]. Available: http://www.colognegamelab.de/institute/cgf/

[24] TH Köln - Entrepreneurs-Club (2020). [Online]. Available: https://www.thkoeln.de/wirtschafts-und-rechtswissenschaften/entrepreneursclub_61578.php 


\section{$4^{\text {th }}$ International Conference on BUSINESS, MANAGEMENT \& ECONOMICS}

[25] TH Köln $-\quad$ Start-up-Service
https://www.thkoeln.de/forschung/gruendungen

[26] TH Köln - Inkubator Südstadt (2020). [Online]. Available: https://www.thkoeln.de/wirtschafts-und-rechtswissenschaften/inkubatorsuedstadt_61592.php

[27] TH Köln - Interdisziplinary Lecture Series Entrepreneurship \& Innovation (2020). [Online]. Available: https://www.th-koeln.de/wirtschafts-undrechtswissenschaften/ringvorlesung-entrepreneurship--innovation_61523.php

[28] TH Köln - Start-up Consulting (2020). [Online]. Available: https://www.thkoeln.de/wirtschafts-und-rechtswissenschaften/start-upberatung 36355.php

[29]TH Köln - StartUpLab@TH Köln (2020). [Online]. Available: https://www.thkoeln.de/forschung/startuplabth-koeln_76381.php

[30] Wirtz, B. W. and Daiser, P. (2018). Business Model Innovation Process: A Systematic Literature Review. Journal of Business Models: Vol. 6 No. 1, pp. 40-58.

[31] Young, J. and Sexton, D. (1997). Entrepreneurial learning: a conceptual framework. Journal of Enterprising Culture: Vol. 5 No. 3, pp. 223-248. 